\title{
Medikal Ekspulsif Tedavi İçin Zaman Doldu Mu?
}

\author{
Ali $\operatorname{Atan}^{1}$
}

${ }^{1}$ Gazi Üniversitesi, Tıp Fakültesi, Üroloji Anabilim Dalı, Ankara

\section{Giriş}

$\ddot{U}$ riner sistem taş hastalığı dünyanın her coğrafyasında bulunan ve her popülasyonu etkileyen bir hastalıktır. Genel olarak üriner sistem taş hastalığı görülme oranı \%1025 arasında değişmektedir (1-3). Günümüzde üriner sistem taş hastalığı tedavisinde kullandığımız yöntemler; izlemgözlem, medikal ekspulsif tedavi (MET), ekstra korporeal şok dalga tedavisi (ESWL), semirijit üreterorenoskopi (URS), retrograd intrarenal cerrahi (RİRC), perkütan nefrolitotomi (standart, mini, mikro PNL) ve son olarak açık cerrahidir (4). Tüm üriner sistem taş hastaları için uygun olan tek bir yöntem yoktur. $\mathrm{Bu}$ yöntemlerden hangisinin seçileceği hastaya ve işlemi yapacak cerraha bağlı olarak değişiklik gösterir. Hastaya ait faktörler; taşın yeri, taşın büyüklüğü ve hastanın anatomik özellikleridir. İşlemi yapacak cerraha ait faktörler ise deneyim ve sahip olunan teknolojidir (5). Bunlara ek olarak hastaların talepleri de tedavi seçiminde önemli rol oynamaktadır. Tedavi seçiminde amaç hastaların komplikasyonsuz ve en ucuz maliyet ile en fazla taştan kurtulmalarıdır. Üriner sistem taş hastalarının önemli bir kısmı ise bir girişim yapılmadan sadece ilaç kullanımı ile taşlarından kurtulmayı istemektedirler. Bu nedenle MET üriner sistem taş hastalığ olan kişiler için önemli seçenek haline gelmiştir. Bu makalede güncel veriler ışı ğında kanıta dayalı olarak MET'nin durumu incelenecektir.

Medikal ekspulsif tedavi ilk olarak 2002 yılında uluslararası literatüre girmiştir (6). Bu çalışmada distal üreterde lokalize taşı olan hastaların \%80.4'ünde alfa-1 bloker tedavisinin taşın düşmesine yardımcı olduğu saptanmıştır. Ayrıca alfa-1 reseptör blokerlerin spazmoanaljezik etkisinin de olduğu gösterilmiştir. Bu tedavi şekli araştırıcıların dikkatini çekmiş ve çok sayıda çalışma yayımlanmıştır. Bu yıldan günümüze internet' de "medical expulsive therapy and urolithiasis" anahtar kelimeleri ile arama yapıldığında 200 üzeri makale olduğu görülecektir. Bu sayılara göre 15 yılda 10 taneden fazla çalışma uluslararası literatürde yayımlanmıştır (7). MET uygulanmasında ilk endikasyon üreterde lokalize < $10 \mathrm{~mm}$ taşlardır. Diğer endikasyonlar ise; URS sonrası üreter taş fragmanları, ESWL sonrası böbrek taşları ve son yıllarda asemptomatik ve $\leq 5 \mathrm{~mm}$ renal kaliks taşları için de MET kullanımıdır (4,8-11). Gebelerde ve çocuk hastalarda bile MET'in kullanılabileceği dair yayınlar vardır (12). MET kararı verilmiş hastalarda ağrı kontrolü iyi, renal fonksiyonlar normal, düzenli radyolojik takip mümkün olmalı ve sepsis bulguları olmamalıdır.

Medikal ekspulsif tedavi için çeşitli medikasyonlar kul- lanılmıştır. Ancak günümüzde elde edilen verilere dayalı olarak kullanılması önerilen tek ilaç alfa-1 reseptör blokeri ilaçlardır. Alfa-1 reseptör blokeri ilaçlar hem taşın üst kısmindaki üreterde peristaltizmin sıklığını ve amplitüdünü hem de taş hizasındaki üreterde spazmı azaltırlar (13). Bu etkinin alfa-1 reseptörlerin dağılımıyla ilgili olduğu gösterilmiştir. Alfa-1 reseptör ekspresyonunun sadece mesane boynu, prostat ve distal üreterde olmadı̆̆ renal pelviste ve kalikslerde de olduğu saptanmıştır. Alfa-1 reseptör ekspresyonu açısından renal pelvis ve kalikslerde farklılık bulunmamiştır (14).

Medikal ekspulsif tedavinin etkinliği açısından uluslararası literatür incelendiğinde çok sayıda çalışmada, sistemik derleme ve meta-analizde MET'in faydalı olduğu görülmektedir (15-23). MET'in üriner sistem taş hastalığında faydalı olduğunu belirten çok sayıda çalışmaya karşın bazı yazarlar metodolojilerinden ve hasta sayılarından dolayı bu çalışmaların verdiği sonuçları sorgulamışlar ve doğruluklarına şüphe ile bakmışlardır. Bu nedenle MET'in faydalı olmadığı yönünde kanaat bildirmektedirler (24). Bu yazarların olumsuz düşüncelerini destekler tarzda bazı klinik çalışmalarda da MET faydalı bulunmamıştır (25-28). Bu çalışmalardan birisinde genel sonuç olarak taş düşme oranını arttırmasa bile alfa blokerlerin taş düşme zamanını kısalttı̆̆ı, ağrıyı ve analjezik ihtiyacını azalttığ 1 belirtilmektedir (26). Ancak bu çalışmalar detaylı incelendiğinde ortalama taş boyutunun $4 \mathrm{~mm}$ den küçük olduğu görülmektedir. Taş boyutundan dolayı bu hastalarda MET'in uygun olmadığı bilinmektedir. Çünkü 2-4 mm arası taşların \%95'inin spontan düşeceği net olarak gösterilmiştir (29). MET için uygun olan hastalarda taş büyüklüğünün 5 mm'den büyük olması gereklidir. Çünkü 5-10 mm arası taşların ise sadece \%50'si spontan düşmektedir $(29,30)$. Bunlar dışında bazı başka çalışmalarda da MET faydasız bulunmuştur. Çok merkezli, randomize, çift kör, plasebo kontrollü bir çalışmada silodosinin etkinliği incelenmiştir. Bu çalışmaya 4-10 mm arası üreterde lokalize taşı olan hastalar alınmıştır. Bütün grup açısından bakıldığında taşların düşmesinde silodosin ile plasebo arasında anlamlı bir fark bulunmamasına karşın çalışmanın sonuç cümlesinde silodosinin distal üreter taşlarının düşmesini arttırdığı belirtilmektedir (31). MET faydasızıdır görüşünü savunanların dayandığı en önemli çalışma İngiltere'de yapılmış 24 merkezin katıldığ 1200 hastanın dahil edildiği SUSPEND çalışmasıdır (32). Bu çalışmada sonuçlar radyolojik kontrolsüz değerlendirilmiştir. Hasta grubu $10 \mathrm{~mm}$ altı üreter taşı olan hastalardan oluşmasına karşın taşların çoğunluğu (75\%) 5 mm'den küçüktür. Alt grup analizinde $>5 \mathrm{~mm}$ taşı olan hastalarda alfa- 1 blokerin 
(\%71.3) plaseboya (\%60.6) göre faydalı olduğu yönünde bir eğilim olduğu belirtilmektedir. Daha yeni bir çalışmada 10 mm'den küçük distal üreter taşı olan hastalarda taşın düşmesi, taşın düşme zamanı, ağrı düzeyi ve analjezik ihtiyacı açısından tamsulosin' in faydalı olmadığı belirtilmesine karşın alt grup analizinde 5-10 mm arası taşlar için tamsulosinin taş düşmesini arttırdığ 1 ve bir kontrendikasyon yok ise bu hastalara tamsulosin verilmesinin uygun olduğu belirtilmektedir (33). Tüm bunlardan çıkarılabilecek sonuç MET faydasız diyen çalışmaların uygun şekilde planlanmadığıdır.

Bu kafa karıştırıcı sonuçlardan sonra 2017 yılında yayımlanmış güçlendirilmiş, randomize plasebo kontrollü çalışmaların incelendiği çok yeni bir meta-analizde de MET'in etkinliği incelenmiştir (34). Bu sistemik derleme ve meta-analizde MET'in faydasız olduğunu düşünen yazarların önceki çalışmalardaki eleştirdikleri noktalar söz konusu değildir. Bu çalışmada incelenen 10 çalışma, «Cochrane araştırma metodoloji» standartları kullanılarak seçilmiştir, bias riski düşüktür ve kanıt düzeyi A sonuçlar sunmaktadır. Bu çalışmanın birincil sonuç ölçümünde alfa reseptör blokerlerin üreter taşlarının düşme oranını arttırdığı saptanmıştır. İkincil sonuç ölçümlerinde alfa reseptör blokerlerinin özelikle $5 \mathrm{~mm}$ üzeri ve distal üreterde lokalize taşların düşmesini arttırdığ 1 ve taş düşme zamanını da kısalttığı gösterilmiştir. Proksimal ve orta üreterde bulunan taşlarda ve 5 mm'den küçük taşlarda bu etki gösterilememiştir. Klinik pratiğimizde önemli rol oynayan Amerikan Üroloji Derneği, Avrupa Üroloji Derneği ve Kanada Üroloji Derneği kılavuzlarında da MET kullanımı önerilmektedir (11).

Tıp, çok dinamik bir bilimdir ve tıpta değişmeyen tek şey değişimdir. Bu nedenle tıpta mutlak doğru ve mutlak yanlış yoktur. Bunun en iyi örnekleri güncel verilere dayalı olarak BPH hastalarında antimuskarinik kullanımı ve prostat kanseri ile testosteron replasman tedavisi arasında bir ilişkinin olmadığının gösterilmesidir. Günümüz verilerine bakıldığında MET faydasız diyen bazı randomize, plasebo kontrollü çalışmalar olmasına karşın daha fazla sayıda randomize, plasebo kontrollü çalışmada, sistemik derleme ve meta-analizde, Cochrane veri analizlerinde ve güncel kılavuz önerilerinde faydalı olduğu belirtilmektedir. Bilim insanları olarak kanitlar doğrultusunda karar vermek durumundayız.

Sonuç olarak tüm üriner sistem taşları için MET kullanımı düşünülmesi doğru değildir. Uygun hastaların seçilmesi ile doğru endikasyonlarda MET kullanımı faydalı görülmektedir. Mevcut veriler 1şığında özellikle distal üreterde lokalize ve $5-10 \mathrm{~mm}$ arası taşlarda MET'in geçerli ve faydalı bir tedavi seçeneği olduğunu söyleyebiliriz.

\section{Kaynaklar}

1. Romero V, Akpinar H, Assimos DG Kidney stones: a global picture of prevalence, incidence, and associated risk factors. Rev Urol 12:86-96; 2010

2. Moe OW. Kidney stones: pathophysiology and medical management. Lancet 367:333-344, 2006

3. Lee YH, Huang WC, Tsai JY et al. Epidemiological studies on the prevalence of upper urinary calculi in Taiwan. Urol Int 68:172-177, 2002

4. Saigal CS, Joyce G, Timilsina AR; Urologic Diseases in America Project. Direct and indirect costs of nephrolithiasis in an employed population: opportunity for disease management? Kidney Int 68:1808-1814, 2005.
5. Wood KD, Gorbachinsky I, Gutierrez J. Medical expulsive therapy. Indian J Urol 30:60-64, 2014

6. Cervenàkov I, Fillo J, Mardiak J, et al. Speedy elimination of ureterolithiasis in lower part of ureters with the alpha 1-blocker-Tamsulosin. Int Urol Nephrol 34:25-29, 2002

7. Gravina GL, Costa AM, Ronchi P, et al. Tamsulosin treatment increases clinical success rate of single extracorporeal shock wave lithotripsy of renal stones. Urology 66:24-28, 2005

8. Naja V, Agarwal MM, Mandal AK et al. Tamsulosin facilitates earlier clearance of stone fragments and reduces pain after shockwave lithotripsy for renal calculi: results from an open-label randomized study. Urology 72:1006-1011, 2008

9. Zheng S, Liu LR, Yuan HC, et al. Tamsulosin as adjunctive treatment after shockwave lithotripsy in patients with upper urinary tract stones: a systematic review and meta-analysis. Scand J Urol Nephrol 44:425-432, 2010

10. Daga S, Wagaskar VG, Tanwar H, et al. Efficacy of Medical Expulsive Therapy in Renal Calculi Less than or Equal to 5 Millimetres in Size. Urology J 13:2893-2898, 2016

11. Kroczak T, Pace KT, Lee JY. Medical Expulsive Therapy: Worthwhile or Wishful Thinking. Curr Urol Rep 18:29, 2017

12. Sowter SJ, Tolley DA. The management of ureteric colic Curr Opin Urol 16:71-76, 2006

13. Karabacak OR, Yilmazer D, Ozturk U et al. The presence and distribution of alpha adrenergic receptors in human renal pelvis and calyces. Urolithiasis 41:385-388, 2013

14. Hollingsworth JM, Rogers MA, Kaufman SR et al. Medical therapy to facilitate urinary stone passage: a meta-analysis. Lancet 368:1171-9, 2006

15. Singh A, Alter HJ, Littlepage A. A systematic review of medical therapy to facilitate passage of ureteral calculi. Ann Emerg Med 50:552-563, 2007

16. Seitz C, Liatsikos E, Porpiglia F, et al. Medical therapy to facilitate the passage of stones: what is the evidence? Eur Urol 56:455-471, 2009

17. Campschroer T, Zhu Y, Duijvesz D, et al. Alpha-blockers as medical expulsive therapy for ureteral stones. Cochrane Database Syst Rev 4:CD008509, 2104

18. Liu C, Zeng G, Kang R, et al. Efficacy and safety of alfuzosin as medical expulsive therapy for ureteral stones: a systematic review and meta-analysis. PLoS One 10:e0134589, 2015

19. Huang W, Xue P, Zong H, et al. Efficacy and safety of silodosin in the medical expulsion therapy for distal ureteral calculi: a systematic review and meta-analysis. Br J Clin Pharmacol 81:13-22, 2016

20. Özsoy M, Liatsikos E, Scheffbuch N, et al. Comparison of silodosin to tamsulosin for medical expulsive treatment of ureteral stones: a systematic review and meta analysis. Urolithiasis 44:491-497, 2016

21. Wang RC, Smith-Bindman R, Whitaker E et al. Effect of tamsulosin on stone passage for ureteral stones: A systematic review and meta-analysis. Ann Emerg Med 69:353-361, 2017

22. Raison N, Ahmed K, Brunckhorst O, et al. Alpha blockers in the management of ureteric lithiasis: A meta-analysis. Int J Clin Pract 71:12917, 2017

23. Wiseman OJ, McClinton S. Int J Surgery 36: 657-659, 2016 
24. Patterson JM, Wiseman OJ. The Role of Medical Expulsive Therapy for Ureteral Stones: Against MET. Eur Urol Focus 3:5-6, 2017

25. Pedro RN, Hinck B, Hendlin $K$, et al. Alfuzosin stone expulsion. Therapy for distal ureteral calculi: a doubleblind, placebo controlled study. J Urol 179:2244-2247, 2008

26. Hermanns T, Sauermann P, Rufibach $K$, et al. Is there a role for tamsulosin in the treatment of distal ureteral stones of $7 \mathrm{~mm}$ or less? Results of a randomised, double blind, placebo-controlled trial. Eur Urol 56:407-412, 2009

27. Ferre RM, Wasielewski JN, Strout TD, et al. Tamsulosin for ureteral stones in the emergency department: a randomized controlled trial. Ann Emerg Med 54:432439, 2009

28. Vincendeau S, Bellisant E, Holgatte A et al. Tamsulosin hydrochloride vs placebo for management of distal ureteral stones: a multicentric, randomized, doubleblind trial. Arch Intern Med 170:2021-2027, 2010

29. Ordon M, Andonian S, Blew B, et al. CUA Guideline: Management of ureteral calculi. Can Urol Assoc J 9:837851, 2015

30. Miller OF, Kane CJ. Time to stone passage for observed ureteral calculi: a guide for patient education. J Urol 162:688-691, 1999
31. Preminger GM, Tiselius HG, Assimos DG et al. 2007 Guideline for the management of ureteral calculi. Eur Urol 52:1610-1613, 2007

31. Sur RL, Shore N, L'Esperance J et al. Silodosin to facilitate passage of ureteral stones: a multi-institutional, randomized, double-blinded, placebo-controlled trial. Eur Urol 67:959-64, 2015

32. Pickard R, Starr K, MacLennan G et al. Medical expulsive therapy in adults with ureteric colic: a multicentre, randomised, placebo-controlled trial. Lancet 386:341349, 2015

33. Furyk JS, Chu K, Banks $\mathrm{C}$ et al. Distal ureteric stones and tamsulosin: a double-blind, placebo-controlled, randomized, multicenter trial. Ann Emerg Med 67:86-95, 2016

34. Amer T, Osman B, Johnstone A et al. Medical expulsive therapy for ureteric stones: Analysing the evidence from systematic reviews and meta-analysis of powered double-blinded randomised controlled trials. Arap J Urol 15:83-93, 2017.

Yazışma Adresi:

Ali Atan,

Gazi Üniversitesi, Tıp Fakültesi, Üroloji Anabilim Dalı, Ankara

Tel: +90 5324242082

e-mail: aliatanpitt@hotmail.com 